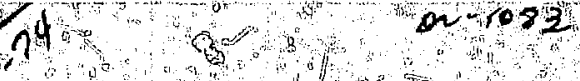

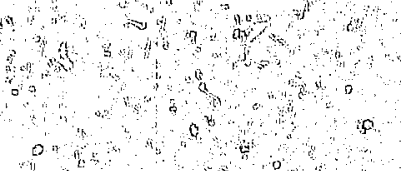

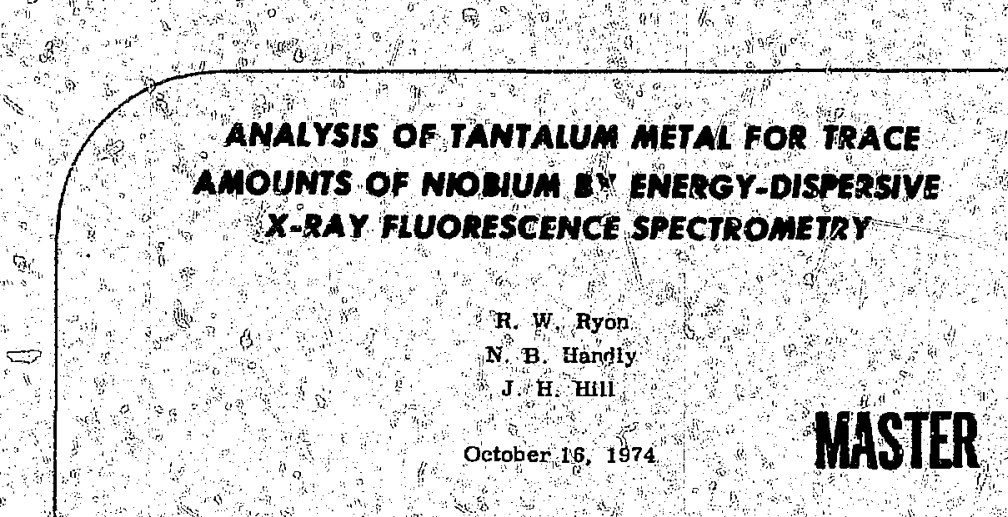

Prepared for US. Atomic Energy Commisstion inder contract No. W-7405-Eng-48

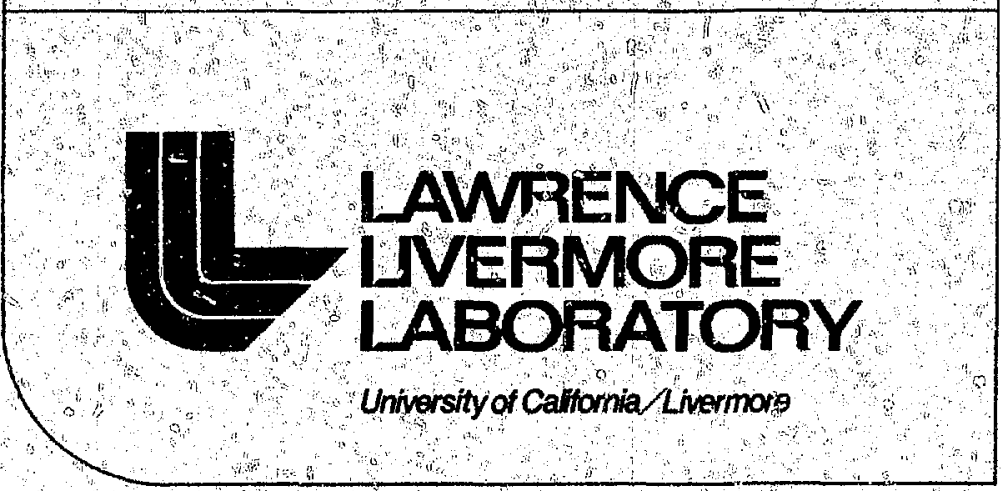

3 



\section{㢟 \\ LAWRENCE LNERMOFE LABORATOFY \\ Chivorsity d Callomia thermore, Cafítonia/94550}

UCRL -51683

\section{ANALYSIS OF TANTALUM METAL FOR TRACE AMOUNTS OF NIOBIUM BY ENERGY-DISPERSIVE $X$-RAY FLUORESCENCE SPECTROMETRY}

R. W. Ryon

N. B. Handly

J. H. Hill

MS. date: October 16, 1974

NOTICE

This ceport was prepred ts accust of work This repaxt was prepured stetes Government. Nelther aponsored by the lnitid States hovem Acomic Fnergy the Urited Sintes nut tire Untred siales A.omis Commlsston, not any of the is employees, nor any or

their contractors, subeontractors, or thele smployees,

their conty warranty, wxpress of implied, or assumes any

makes any war resonsibility for the accuracy, com-

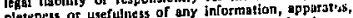

pletents of userulicss of any fincoresents thes its ust

product or process disclosed, or lepresents 


\title{
ANALYSIS OF TANTALUM METAL FOR TRACE AMOUNTS OF NIOBIUM BY ENERGY-DISPERSIVE X-RAY FLUORESCENCE SPECTROMETRY
}

\begin{abstract}
A nondestructive method is described for quantitatively measuring trace amounts (0-500 ppm) of niobium in tantalumniobium alloy sheets, turnings, and fabricated parts. The method, which

makes use of an energy-dispersive $x$-ray spectrometer to compare the sample to be analyzed against known standard samples, can detect niobium levels as low as $10 \mathrm{ppm}$.
\end{abstract}

\section{Introduction}

Our need was to measure trace concentrations of niobium in tantalum-niobium alloy accurately, nondestructix ely, and fairly rapidly. $X$-ray fluorescence is the ideal method. We chose to use our energydispersive spectrometer rather than our wavelength instrument because its large sample chamber can accommodate the diversity of sizes and shapes of the pieces of material to be analyzed, and because the primary and fluorescent beams are easily filtered.

The energy-dispersive spectrometer and its operating characteristics are described in UCRL -75108.1

The epectrometric analysis depends on comparing $x$-ray fluorescence measurements made on the Ta-Nb material to be

${ }^{1}$ Richard W. Ryon, Determination of Trace Impurities in Boron Carbide by Energy Dispersive X-Ray Fluorescence spectrometry, 1, Lawrence Livermore Laboratory kept. UCRL -75108 Preprint (1974). analyzed with the same measurements made on $\mathrm{Ta}-\mathrm{Nb}$ reference samples whose Nb content is precisely known. We made our own reference samples out of disks punched from Ta-Nb sheet containing various trace concentrations of $\mathrm{Nb}$. To determine the $\mathrm{Nb}$ content of the reference samples we first used the spectrometer to obtain a primary calibration curve which showed the specirometer's response to various accurately prepared solutions of Ta with different concentrations of $\mathrm{Nb}$. Solutions made from the same sheets as the reference samples were then run to determine their Nb content by comparing the spectrometer response with the primary calibration curve. The reference sample disks were also analyzed for $\mathrm{Nb}$ content by neutron activation analysis, and the results were very close to those obtained from the $x$-ray fluorescence measurements.

Once the reference samples had been establighed we were able to put our 
analysis technique into operation. The procedure is simply to take a sample that is to be analyzed and run it in the $x$-ray spectrometer, then run the reference samples to obtain a calibration curve with which to determine the $\mathrm{Nb}$ concentration in the sample being analyzed.

\section{Standardization}

To determine the $\mathrm{Nb}$ content of the reference sample disks, we first prepared primary solution standards from highpurity tantalum and niobium metal. A stock solution of $\mathrm{Nb}$ was prepared by dissolving $0.1000 \mathrm{~g}$ of $\mathrm{Nb}$ shot with HF Bolution in a Tellon beaker and then

"Reference to a company or product name does not imply approval or recommendation of the product by the University of California or the U.S. Atomic Energy Commission to the exclusion of otherg that may be suitable. diluting to $100.0 \mathrm{ml}$ with $10 \% \mathrm{HF}$. Samples of Ta turnings weighing 1.0000, 0.999g, $0.9998,0.9997,0.9995,0.9993$, and $0.9990 \mathrm{~g}$ respectively were dissolved in $\mathrm{HF}-\mathrm{HNO}_{3}$ solution in Teflon beakers. Aliquote of the Nb stock solution containing $0,100,200,300,500,700$, and $1000 \mu \mathrm{g}$ Nb were added to the respective Ta solutions, which gave for each $1.0000 \mathrm{~g}$ total of metal ions. Each sanple was then made up to $25.00 \mathrm{ml}$ with $10 \%$ HF solution. These solutions were used to prepare the

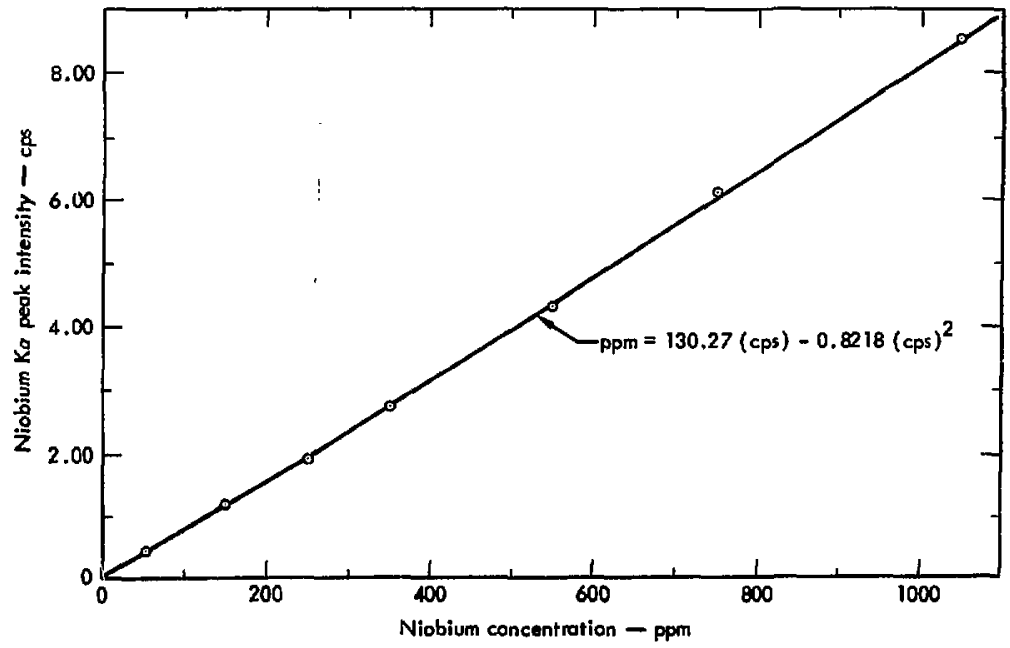

Fig. 1. Primary calibration curve obtained with the atondard solutions of Ta-Nb. This curve was used to determine the Nb concentration in the reference sample disks. 


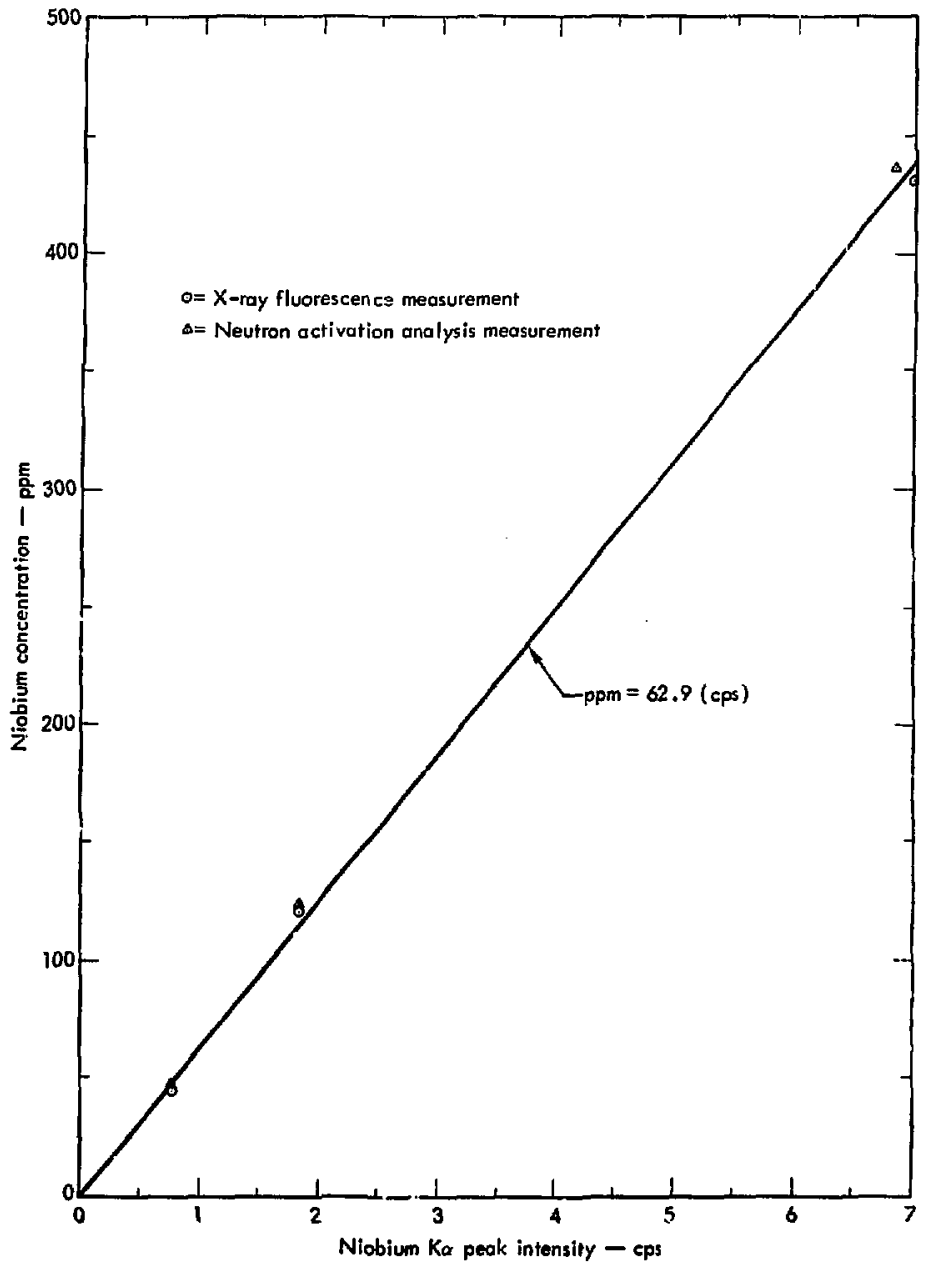

Fip 2. Calibration curve obtained with the reference sample disks, used to convert $\mathrm{Nb} \mathrm{K} \alpha$ counts per second in a sample heing analyzed to ppm of $\mathrm{Nb}$. 
primary calibration curve in Fig. 1 by $x$-ray fluor escence (XRF) as described below. (Nore: The intercept was $49.7 \mathrm{ppm}$ Nb due to the trace amount of niobium in the stock tantalum. Thit has been corrected for in the Figure.)

The Ta-Nb alloys from which the disks were punched were dissolved in $\mathrm{HF}-\mathrm{HNO}_{3}$ solution and diluted with $10 \% \mathrm{HF}$ to give solutions containing 1.0000 g metal per $25.00 \mathrm{ml}$. The $\left.\mathrm{N}_{1}\right)$ content of each of these solutions was determined by comparing the $\mathrm{Nb}$ Ka peak intensity with the solution primary calibration curve previously prepared.
Three of the four disks were sub-. sequently analyzed by neutron activation analysis (NAA) using $15-\mathrm{MeV}$ neutrons for excitation and gamma spectroscopy for measurement." The XRF and NAA values agree remarkably well (Fig, 2), having a correlation coefficient $\mathbf{r}$ greater than 0.99 .

After they were polished with $5-\mu \mathrm{m}$ alumina, the disks served as standards for all subsequent analyses. The calibration curve obtained with the disks is given in Fig. 2.

\footnotetext{
Analyses performed by D. Nethaway and $M$. Coops of the LLI Radiochemistry Division.
}

\section{X-Ray Fluorescence Procedure}

A tungsten $x$-ray tube operating at $35 \mathrm{kV}$ and $30 \mathrm{~mA}$ is used to excite the niobium characteristic spectrum. The primary beam is filtered with $0.020-i n$. $(0.05-\mathrm{cm})$ tin foil to recluce the bremsotrahlung which would ctherwise add to the spectrum background and thereby lower the measurement precision.

The fluorescent radiation is filtered with $0.020-$ in. aluminurn foil to attenuate the $\mathrm{Ta} \mathrm{L}$-radiation. Tris is necessary because there are double photon peaks which result from incornplete pulse pileup rejection in the amplifier. These peaks fall in the same spectral region as the $\mathrm{Nb}$ $K-$ radiation. If the flucrescent beam is unfiltered, the double photon peaks are so Intense that trace analyais is impossible.

$5.00-\mathrm{ml}$ aliquots of the solutions to be neasured were pipetted into 1 -in.-diam (2 $5-\mathrm{cm})$ plastic Spex cups which were then covered with $0.00025-1 \mathrm{~h}$. $(64-\mu \mathrm{m})$ Mylar film. The Ta $L \beta$ peak from each solution is used to normalize all measurements. This procedure reduces the experimental scatter of data due to voltage, current, and specimen differences. The Nb Ka peak is integrated over a range of $0.32 \mathrm{keV}$ (17 channels) with a straight-line background subtraction. The results for the standard solutions are shown in Fig. 1. The concentration of $\mathrm{Nb}$ in the disks was determined by comparing the $\mathrm{Nb} \mathrm{Ka}$ intensity from their respective solutions with the standard solution curve.

The Ta-Nb alloy disks themselves were then measured by $x$-ray nuorescence using the same procedure as above in order to determine a working curve. The results are given in Fig. 2. When the data are normalized to $38,00 \mathrm{cps}$ (counts/sec) for the Ta $I \beta$ peak $(0.32 \mathrm{keV}$ wide), the sengitivity for $\mathrm{Nb} K \alpha$ is $0.0159 \mathrm{cps} / \mathrm{ppm}$. This calibration factor is checked each day that analyses are run. 


\section{Applications}

The minimum detectable level of niobium in tantalum is $10 \mathrm{ppm}$ for a halfhour counting time using the method described above. (Both the detectable level and the measurement error decrease with the square root of the time epent counting.)

We have analyzed about 40 specimens to date. These include turnings, machined parts, tensile strength specimens, and rolled sheets. Concentrations observed fall in the range 0-500 ppm. As an example of the precision obtained, both a machined part and the turnings from that part were analyzed. The results were:

$$
\begin{array}{ll}
\text { Part: } & 390 \pm 9 \mathrm{ppm} \\
\text { Turnings: } & 412 \pm 27 \mathrm{ppm}
\end{array}
$$

The indicated error range is $3 \sigma$ based on counting statistics $=3$ (peak plus background counts) ${ }^{1 / 2}$. 